\title{
Soils' classification according to their seismic properties in Building Codes of various countries
}

\author{
Vladislav Zaalishvili* \\ Geophysical Institute of the Vladikavkaz Scientific Center of the Russian Academy of Sciences, \\ 362002, Vladikavkaz, Russia
}

\begin{abstract}
The article presents the results of Building Codes' analysis in different countries of the world in terms of taking into account the seismic properties of soils when calculating buildings and structures for seismic effects. The main indicators of the soils' seismic properties are highlighted, their analysis is carried out from the point of view of the possibility and necessity of taking them into account in the future Building Codes of Georgia. The basis for the soils' classification according to their seismic properties has been developed. The conclusion about the validity of using the new Building Codes of Russia and the Building Codes of the United Europe (Eurocode-8) is made as the basis for future Russian standards in terms of taking into account the seismic properties of soils by their seismic properties. The paper indicates that the new Building Codes in Russia will be developed based on the Building Codes of the former USSR. The main provisions of the standards have been tested in practice and, if the construction is in accordance with them, buildings and structures withstand seismic effects well. These Regulations do not contradict the Eurocode- 8 Standards, which are undoubtedly more progressive and can be taken as a basis for future Building Codes in Russia. In conclusion, the main criteria for the soils' classification according to their seismic properties are given.
\end{abstract}

\section{Introduction}

In recent years, the list of studies, in which instrumental measurements are very actively used in various, very different fields of geophysics, has significantly expanded. This undoubtedly raises the quality of the results obtained as well as their reliability [1-6]. In this regard, the problem of the soils' classification reliability is of particular interest.

\section{Soils' classification according to their seismic properties}

The soils'classification according to their seismic properties, as a rule, is given in the relevant Building Codes of different countries in the world. We have studied the Building Codes of 37 countries in the world [7]. In accordance with the above-mentionedstandards,

\footnotetext{
*Corresponding author: vzaal@mail.ru
} 
in each individual country, differentiation of different soils according to their seismic properties occurs depending on the country's experience, construction culture and on the basis of relevant traditions. The answer to a very important question, which soil characteristics are the main ones in these regulatory documents, is given in Table 1. But the answer to the question of the number of characteristics used by the standards of a particular country is considered in Table 2. It should be noted that in some countries such differentiation is either completely absent, or reaches 7 (Table 3). Similar lists or classification tables are generally not used in Italy, Romania, El Salvador and Taiwan. On the other hand, the division of soils into different categories according to their seismic properties is the maximum in terms of their number ( 5 categories) in Turkey and Australia (Table 4). From this point of view, the formal statistics of accounting for certain soil indicators in various countries of the world shows a very interesting picture. On the other hand, no less scientific and practical interest is caused by such Building Codes that have been developed by the scientists and experts from the leading foreign countries.

Those issues that should be clarified or developed taking into account, on the one hand, the peculiarities of the engineering and seismological conditions in Russia, and on the other hand, taking into account the Building Codes of the European Union (Eurocode 8) and Building Codes of other advanced foreign countries (USA, Canada, etc.) are considered below.

The analysis of these classifications provides a basis for the creation of new types of classifications proper, i.e., taking into account the value of the soil seismic coefficient (its more accurate values for taking into account more adequate calculation of seismic forces in the future formula). It should be noted that according to the considered Building Codes, the soil coefficient characterizes the deterioration of the physical and mechanical properties of soils, respectively. An exception is the draft Regulations of Russia and the European Union(Eurocode 8) [8,9]. Here, the deterioration of soil characteristics is taken into account by the nonlinearity of soils, which is expressed by the introduction of a special coefficient of nonlinearity (in Russia 1-0.7 and Eurocode 8 - 1-0.9).

Table 1. Number of categories in Building Codes of different countries

\begin{tabular}{|c|c|c|}
\hline Soil categories, number & Countries & Percentage, $\%$ \\
\hline 1 & 4 & 11 \\
\hline 2 & 3 & 8 \\
\hline 3 & 16 & 43 \\
\hline 4 & 11 & 30 \\
\hline 5 & 3 & 8 \\
\hline
\end{tabular}

Table 2. Soil characteristics in the standards of different countries

\begin{tabular}{|c|l|c|c|}
\hline No. & \multicolumn{1}{|c|}{ Soil characteristics } & $\begin{array}{c}\text { Countries, } \\
\text { number }\end{array}$ & Percentage, \% \\
\hline 1. & Lithological description & 32 & 100 \\
\hline 2. & Layer thickness & 7 & 22 \\
\hline 3. & $\begin{array}{l}\text { The seismic waves' propagation } \\
\text { velocity in the soil }\end{array}$ & 6 & 19 \\
\hline 4. & $\begin{array}{l}\text { Mechanical and deformation } \\
\text { characteristics }\end{array}$ & 11 & 35 \\
\hline 5. & Water level in soils & 18 & 56 \\
\hline 6. & Prevailing period & 7 & 22 \\
\hline
\end{tabular}




\begin{tabular}{|c|l|c|c|}
\hline 7. & Physical characteristics & 4 & 13 \\
\hline 8. & Standard penetration & 3 & 10 \\
\hline 9. & Types of bases and types of soils & 7 & 22 \\
\hline 10. & Relief & 2 & 6 \\
\hline
\end{tabular}

According to Eurocode 8, only for temporary and less important purposes of structures, while located in an area with moderate seismicity, you can use the table of soil classifications [9]. As already noted in Italy, Romania, El Salvador and Taiwan, such tables are not used at all, but in Russia and Uzbekistan they are used only in the absence of seismic microzoning maps. In the USA and Japan, the marked classifications are refined as a result of special studies, etc.

The variety of soil classifications in Building Codes of different countries of the world and differences in the ways of specifying the values of the soil coefficient once again confirm the need to carry out the work on seismic microzoning and, in fact, is the only adequate scientific approach for determining the seismic properties of soils or their categories.

Table 3. The number of soil indicators in the standards of different countries in the world

\begin{tabular}{|c|c|c|c|}
\hline No. & $\begin{array}{c}\text { Soil indicators, } \\
\text { number }\end{array}$ & Country, number & Percentage, $\%$ \\
\hline 1. & 1 & 5 & 15 \\
\hline 2. & 2 & 8 & 23 \\
\hline 3. & 3 & 10 & 30 \\
\hline 4. & 4 & 3 & 9 \\
\hline 5. & 5 & 4 & 12 \\
\hline 6. & 6 & 3 & 9 \\
\hline 7. & 7 & 1 & 3 \\
\hline
\end{tabular}

Table 4. Accounting for soils in Building Codes

\begin{tabular}{|c|c|c|c|c|c|c|c|}
\hline \multirow[t]{2}{*}{ No. } & \multirow[t]{2}{*}{ Country } & \multirow{2}{*}{$\begin{array}{c}\text { Soil } \\
\text { categories, } \\
\text { number }\end{array}$} & \multicolumn{5}{|c|}{$\begin{array}{l}\text { Soil coefficient, according to soil } \\
\text { categories }\end{array}$} \\
\hline & & & 1 & 2 & 3 & 4 & 5 \\
\hline 1 & 2 & 3 & 4 & 5 & 6 & 7 & 8 \\
\hline 1. & $\begin{array}{c}\text { European } \\
\text { Union } \\
\text { (Eurocode 8) }\end{array}$ & 3 & 1.0 & 1.0 & $\begin{array}{l}0.9 \\
(1.4)\end{array}$ & - & - \\
\hline 2. & Russia & 3 & 1.0 & $\div$ & 0.7 & - & - \\
\hline 3. & USA & 4 & 1.0 & 1.2 & 1.5 & 2.0 & - \\
\hline 4. & Armenia & 4 & 0.8 & 1.0 & 1.2 & 1.4 & - \\
\hline 5. & Turkey & 4 & - & - & - & - & - \\
\hline 6. & Greece & $4+1 *$ & 0.85 & 1.0 & 1.25 & 1.3 & - \\
\hline 7. & Japan & 3 & - & - & - & - & - \\
\hline 8. & Australia & 5 & 0.67 & 1.0 & 1.25 & 1.5 & 2.0 \\
\hline 9. & Argentina & 3 & - & - & - & - & - \\
\hline 10. & Canada & 4 & 1.0 & 1.3 & 1.5 & 2.0 & - \\
\hline 11. & Columbia & 3 & 1.0 & 1.2 & 1.5 & - & - \\
\hline
\end{tabular}




\begin{tabular}{|c|c|c|c|c|c|c|c|}
\hline 12. & France & 4 & 1.0 & $\div$ & $\div$ & 1.5 & - \\
\hline
\end{tabular}

*)- not included in the main classification.

The scientists and specialists from Japan have been considered the experts of the highest qualification in the field of engineering seismology and earthquake-resistant construction for a decade. Their approaches have been widely used around the world and have been imitated. With the active participation of Japanese experts, for example, the maps of seismic hazard were developed in Mexico, Portugal, Spain, etc. Comparison and analysis of the engineering macro-seismic material of the recent strong and destructive earthquakes Northridge (USA, 1994) and Kobe (Japan, 1995) clearly showed and proved a higher level of US seismic hazard maps. This created such a critical situation that after studying the consequences of the Kobe earthquake in 1995, by the decision of Japanese experts, the accelerated development and updating of Building Codes in Japan began.

On the other hand, during the Neftegorsk earthquake (Russia, 1995), 2/3 of the shift camp population perished. The real intensity of the manifested earthquake exceeded the expected level by 2-3 points (according to the General Seismic Zoning Maps of Russia). The analysis of the macro-seismic survey results, despite the large number of destroyed houses, showed the high level of Soviet Regulationsonce again. The buildings constructed without anti-seismic measures were destroyed. The buildings designed for a minimum seismicity of 7 points, and in which the corresponding anti-seismic measures were implemented, withstood the effects of a 9-point earthquake.

All this led to the fact that the Building Codes of the former USSR were used as the initial Regulations for the creation of new construction National Regulations of Georgia [4]. It was on their basis that new Building Codes in Russia were developed, and it was taken into account when developing Eurocode 8. For example, only two standards can take into account the nonlinearity of soils. In this regard, it should be noted that the well-known expert in the field of earthquake-resistant construction, the American scientist Michael Trifunac, in his latest work calls on scientists in the field of earthquake-resistant construction of the United States and other countries of the world to take into account the nonlinearity of soils in Building Standards and when conducting seismic microzoning [5].

Currently, in Georgia, with the active participation of the author, Building Codes have been developed on the basis of the Building Codes'concept of the former USSR and Eurocode 8 . These Regulations were submitted for consideration and subsequent approval to the Ministry of Construction and Urbanization of Georgia.

A lot of work is currently underway to create the new Regulations for Russia. In this regard, in the future, it is necessary, in our opinion, to solve the following tasksfor the development and improvement of modern Building Codes.

Based on the peculiarities of the engineering-geological and geomorphological conditions of Russia, it is necessary to clarify the classification of the soils'seismic properties, which should be based on the results of the work carried out earlier by the institute on seismic microzoning and the data of engineering-geological studies. In particular, it is necessary to clarify the optimal number of soil categories. In our opinion, the number of soil categories according to their seismic properties should be 4 categories. This requires further systematization of the available engineering-geological material and its subsequent formalization. To solve this issue, modern methodologies (approaches and technologies) for the formation and interaction of databases will be used.

Particular attention should be paid to the choice of soil features, characterized by the adequate indicators, and the choice of their number (lithological descriptions, physical and mechanical characteristics, shear wave velocity in soils, penetration number, etc.). The study of Building Codesin the world showed the need to analyze the problem of the need to use the basic and additional characteristics of soils. On the one hand, this will add 
concreteness to the Regulations, and on the other hand, it will complicate the formalization of data and the classification itself. It should be noted that the ideology for the development of any Regulations should be based on the concept that the use of one or another soil classification should be implemented only in the absence of seismic microzoning maps and only for the preliminary conclusions. It should be clear to the designer and builders that the use of this table additionally increases the inaccuracy of the final results and its widespread use is excluded. Eurocode 8 gives a similar recommendation.

The basic physical and mechanical characteristics of soils should be included in Building Codes. When solving this problem, special attention should be paid to the existing data and the boundary conditions of the classification. We are talking about the adequate use of indicators in the form of instrumental determination of the seismic properties of soils (consistency indicator, porosity of soils, penetration number, deformation moduli, etc.). The existing material will form the basis for a reliable seismic soil classification. It is equally important to use the value of the shear wave propagation velocities in soils for the needs of classifications. This parameter is widely used in the standards of various countries of the world. Currently, in Russia there are a large number of measurements of this parameter in various soils, although, unlike Georgia, they are still not included in the database.

Particular attention in the Standards should be given to the soil thickness to be investigated. But based on the study and analysis of the material of macro-seismic survey of strong earthquakes (Mexico, 1985; Spitak, 1988, etc.), a very important influence of this parameter on the manifestation of earthquakes by the thickness of the soil was established. This circumstance has been taken into account in Building Codes around the world. In the corresponding classifications, this parameter varies within 5-30 m for the rocky soils, 20-70 $\mathrm{m}$ for the soils of medium seismicity and $6-30 \mathrm{~m}$ for the so-called soft soils. To account for more powerful soil massifs, special calculation methods are used. Unfortunately, this circumstance has been reflected in the Russian Regulations for quite a long time (here we are talking only about the traditional 10-meter soil layer). Currently, the Russian Standards are investigating 30-meter soil thickness.

Finally, it is necessary to clarify the influence and magnitude of the so-called "soil coefficients" not used in the Russian Standards. In this case, any type of soil or category, as a rule, corresponds to a certain value of the soil coefficient. In almost all Building Codes of the world, with the deterioration of seismic properties, the value of this coefficient increases. It is interesting to note that the first editions of Building Codes (1997) did the same [12]. At the same time, with the transition from the first to the third category, the corresponding soil coefficient varied within $0.7-1.4$, which was close to the world data. On the other hand, the analysis of strong earthquakes found that the seismic effect is significantly influenced by the nonlinear properties of soils, or the so-called "nonlinearity". We are talking about the nonlinearity of the stress-strain relationship, which is clearly observed under strong seismic impacts or under the conditions of significant deformations. When solving this issue, i.e., accounting for nonlinearity in the Building Codes of Russia, it is necessary to clarify such soils, their prevalence in the country and their behavior under heavy loads. In the draft of the new Building Codes of Russia, which were not subsequently approved [12], the coefficient of nonlinearity in the transition from the category I of soils to the category III, varied within 1-0.7. In Eurocode 8, when moving from the category I of soils to the category III, this indicator changes in the range of 1-0.9. In this regard, the new Regulations need a clear definition of the nonlinearity concept. Clarification of its value should be clarified using the calculation formula for determining seismic forces. 


\section{Conclusion}

The analysis of the existing Seismic Regulations of different countries of the world has been carried out. Based on the peculiarities of the engineering-geological and geomorphological conditions of Russia, it is necessary to clarify the classification of the seismic properties of soils, which should be based on the results of the work carried out earlier by the institute on seismic microzoning and the engineering-geological studies data. It is necessary to determine the optimal number of soil categories. This requires the systematization of the existing engineering and geological material and its subsequent formalization. To solve this issue, modern methodologies for the formation and interaction of databases will be used.

Particular attention should be paid to the choice of soil features, characterized by adequate indicators, and their number (lithological descriptions, physical and mechanical characteristics, shear wave velocities in soils, penetration number, etc.). The study of the Building Codes of the world showed it is necessary to analyze the problem of the need to use the basic and additional soils'characteristics. On the one hand, this will add concreteness to the Regulations, and on the other hand, it will complicate the formalization of data and the classification itself. At the same time, it should be noted that the ideology of any modern Regulations'development should be based on the concept that the use of one or another soil classification should be implemented only in the absence of seismic microzoning maps and only for the preliminary conclusions. It should be clear to designers and builders that the use of this table additionally increases the error of the final results and its widespread use is excluded. Eurocode 8 gives a similar recommendation.

The Building Codesshould include the basic physical and mechanical characteristics of soils. When solving this issue, special attention should be paid to the existing data and boundary conditions of the classification.

Particular attention should be paid to the soil thickness to be investigated. Based on the study and analysis of the macro-seismic survey material of strong earthquakes, the influence of the soil thickness on the earthquakes'manifestation should be established. In the corresponding classifications, this parameter varies within $5-30 \mathrm{~m}$ for the rocky soils, 20-70 $\mathrm{m}$ for the soils of medium seismicity and 6-30 $\mathrm{m}$ for the so-called soft soils.

It is necessary to clarify the influence and values of the so-called. ground coefficients are weaker than their use. Any type of soil, assigned to one or another category, usually corresponds to a certain soil coefficient. In almost all Building Codes of the world, with the deterioration of seismic properties, the value of this coefficient increases. In the draft of new Building Codes of Russia, which were not subsequently approved, the coefficient of nonlinearity changed, in the transition from the category I of soils to the category III, within 1-0.7. In Eurocode 8, this indicator varies between 1-0.9. At the same time, the standards require a more precise definition of the nonlinearity concept. Refinement of its value should be made using the calculation formula for determining seismic forces.

A wide variety of classifications, variegation and difference in the rules or approaches for determining the soil coefficients in Building Codes of different countries in the world once again proves the need for seismic microzoning and indicates its results as the only adequate scientific approach for determining the soils'seismic properties.

\section{References}

1. V.B. Zaalishvili, International Journal of GEOMATE 10(2), 1706-1717 (2016)

2. AV Gorbatikov, EA Rogozhin, MYu Stepanova, YuV Kharazova, et.al. The Earth Physics 1, 28 (2015) 
3. V.B. Zaalishvili, D.A. Melkov Izvestiya. Physics of the Solid Earth 50(5), 707-718 (2014).

4. G.S. Grigorkina, A.G. Ramonova, D.D. Kibizov, E.N. Kozyrev, V.B. Zaalishvili, T.T. Magkoev, K. Fukutani, Solid State Communications 257, 16-19 (2017).

5. K.K. Khulelidze, Yu.I. Kondratyev, V.B. Zaalishvili, Z.S. Betrozov Sustainable development of mountainous areas 8(1), 46-51 (2016).

6. A. Shempelev, V. Zaalishvili, S. Kukhmazov, Geotectonics 51(5), 479-488 (2017).

7. M. Paz, International Handbook of Earthquake Engineering (Chapman \& Hall, 1994).

8. Building Codes and Regulations, Moscow, 2000.

9. Eurocode 8. European Prestandard ENV 1998-1-1. Design provisions for earthquake resistance of structures. Part 1-1.6, pp. 11-12

10. Building Codes and Regulations (SNIP II-7-81)(Moscow, Stroyizdat)1982 49.

11. M. Trifunac, Novikova, Earthquake Engineering and Structural Dynamics 9 (1998).

12. Building Codes and Regulations. Construction in seismic areas (first edition) (Moscow, Gosstroy of Russia) 1997. 